\title{
A NEGAÇÃO DA ALTERIDADE E A NECROPOLÍTICA
}

\author{
LA NEGACIÓN DE LA ALTERIDAD Y LA NECROPOLÍTICA
}

\author{
Lourival Robty Santos de Souza* \\ Lauro Barros Barreto**
}

\begin{abstract}
RESUMO
A temática desta pesquisa surge do desejo de filosofar e da intuição investigativa que percebe as estruturas políticas em estado de corrosão perante a alteridade, desde a perspectiva do filósofo Emmanuel Levinas, e o cenário da necropolítica denunciado pelo filósofo Achille Mbembe diante de sua crítica à sociedade contraditoriamente democrática e escravagista. Para isso serão retratadas realidades contemporâneas de vida humana, como o paradigma da violação da integridade física, moral e da própria vida em si diante do cenário da população carcerária negra, por exemplo. O mecanismo da necropolítica oferece relações em estado de ruína, devido a sua política de morte, a sua assistência para fortalecer as desigualdades, exemplificado na população carcerária, e a violência institucionalizada. Ao adentrar nas experiências contemporâneas de destruição humana, faz-se necessário identificar os envolvidos na contenda como sujeitos de negação ou afirmação da alteridade. O objetivo desta investigação será analisar a negação da alteridade e os mecanismos da necropolítica que violam e ceifam a vida.
\end{abstract}

PALAVRAS-CHAVE: Necropolítica. Alteridade. Ética. Presidiários.

\section{RESUMEN}

El tema de esta pesquisa surge del deseo de filosofar y de la intuición investigativa que percibe las estructuras políticas en un estado de corrosión frente a la alteridad, desde la perspectiva del filósofo Emmanuel Levinas, y el escenario de la necropolítica denunciada por el filósofo Achille Mbembe ante su crítica a sociedad contradictoria democrática y de esclavitud. Con este fin, se retratarán las realidades contemporáneas de la vida humana, como el paradigma de la violación de la integridad física, moral y la vida misma frente a la población carcelaria negra, por ejemplo. El mecanismo de necropolítica ofrece relaciones en mal estado, debido a su política de muerte, su asistencia para fortalecer las desigualdades, ejemplificadas en la población carcelaria, y la violencia institucionalizada. Al ingresar a las experiencias contemporáneas de destrucción humana, es necesario identificar a los involucrados en la disputa como sujetos de negación o afirmación de la alteridad. El objetivo de esta investigación será analizar la negación de la alteridad y los mecanismos de la necropolítica que violan y cierran la vida.

PALABRAS CLAVE: Necropolítica. Alteridad. Ética. Reclusos.

\footnotetext{
* Graduado em Filosofia pelo Instituto Santo Tomás de Aquino e pós-graduado em aconselhamento filosófico pelo Claritiano Centro Universitário. E-mail: lourivalrobty@gmail.com.

** Centro Universitário Leonardo da Vinci. E-mail: laurobarros2016@gmail.com.
} 


\section{A NEGAÇÃO DA ALTERIDADE E A NECROPOLÍTICA}

O título deste artigo surge do desejo de filosofar e da intuição investigativa que percebe as estruturas políticas em estado de corrosão perante a alteridade, desde a perspectiva levinasiana, e o cenário da necropolítica denunciado por Mbembe diante de sua crítica à sociedade contraditoriamente democrática e escravagista.

Emmanuel Levinas será apresentado neste texto para corroborar com o pensamento de Achille Mbembe, quando este critica a racionalidade política e afirma a existência personificada da necropolítica enquanto uma política da morte. Para isso serão retratadas realidades contemporâneas de destruição humana, como o paradigma da violação da integridade física, moral e da própria vida em si diante do cenário da população carcerária negra, por exemplo.

A ética da alteridade estará posta para dialogar com os desafios encontrados na necropolítica, visto que este conceito fundado por Mbembe difunde a vulnerabilidade em que se encontra a vida cedida à morte, nas relações macro (Estado-Sociedade) e nas relações micro (Eu-Outro). Sob essa ótica, atualizaremos a afirmação de que a ética é a filosofia primeira, e que sua ausência nas relações interpessoais será a evidência da negação da alteridade.

O objetivo desta investigação será analisar a negação da alteridade e os mecanismos da necropolítica que violam e ceifam a vida. Assim, seguiremos a exigência ética em seu incansável movimento, "ninguém pode dizer em momento algum: cumpri todo o meu dever. Excepto o hipócrita... É neste sentindo que há uma abertura para além do que se delimita; e tal é a manifestação do infinito [...] é o espaço por onde o Infinito entra na linguagem, mas sem se deixar ver" (LEVINAS, 1982, p. 97-98).

\section{A CRÍTICA À RACIONALIDADE}

Os argumentos filosóficos de Levinas e Mbembe partem da crítica à racionalidade moderna, que coisificou a existência humana à razão, ou seja, o outro, antes tomado no esquema sujeito-objeto, era reduzido às categorias da razão e se findava no filtro daquilo que era categorizado pelo conhecimento.

Levinas, segundo Lovo (1999), propôs o contrário ao romper o esquema simétrico sujeito-objeto, colocando o outro numa percepção horizontal da relação, uma percepção da 
relação Eu-Outro. Isso significa que essa filosofia traz de volta este Outro, não ao campo do conhecimento, mas sim, ao campo da ética. Sai-se do campo da instrumentalização radical da epistemologia do Outro - da questão do como conhecer - e parte-se para o campo da ética, em que este Outro é o elemento primeiro e fundante da subjetividade do sujeito dado em relação.

Abrir-se a essa tomada de consciência é possível quando se retorna da travessia da racionalidade moderna. Sustentar que a razão e sua racionalidade possui uma unidade capaz de decodificar as relações interpessoais, significaria o acobertamento deste modo de pensar e a negação de outros tipos de racionalidade, primordialmente ética, possível e real, tal qual estamos apontando; tem que apontar para a desidentificação desse modo de conceber o sujeito em suas relações, purificar seu existir presente a partir da ética da alteridade, que se esclarece na citação:

Esse modo de pensar a alteridade rompe com o paradigma de que a liberdade é uma atitude da existência envolvida apenas por si mesmo, em que os outros são apenas os atingidos quando são interpelados. A alteridade propõe uma relação de responsabilidade, quando há a interpelação do rosto do outro, que invoca o ordenamento do cuidado. (SOUZA, 2019, p. 393).

Essa responsabilidade apontada, de origem levinasiana, quer atravessar essa repetição de ver o Outro e tantos Outros como o Mesmo do sujeito, em que é transferida sua condição de existência de modo simétrico e em sua similitude ao Outro. Faz-se necessário dar-se ao reconhecimento e ao sentir de uma nova consciência, capaz de transformar o refletir e o agir humano: ser capaz de responsabilidade.

Aquilo que até então não fazia parte do universo desse Sujeito, que outrora esteve obrigando o Outro a ser seu objeto experimental, é cessado graças ao apontamento da ética como causa primeira e inaugural do existir humano. O sujeito é levado a reconsiderar sua experiência e conceber a verdade de que quem o inaugura no mundo das relações é o Rosto do Outro.

\footnotetext{
Mas penso que, seja qual for a motivação que explique essa inversão, a análise do rosto tal como acabo de fazer, com o domínio de outrem e da sua pobreza, com a minha submissão e a minha riqueza, é primeira. É o pressuposto de todas as relações humanas. Se não existisse, nem sequer diríamos, diante de uma porta aberta: Primeiro o Senhor! É um 'Primeiro o Senhor!' original que eu procuro descrever. (LEVINAS, 1982, p. 81).
}

Este modo de responder às relações cotidianas parece estar comprometido quando, segundo Mbembe (2016), ao compor sua crítica à racionalidade moderna, notou que o 
conceito de razão fora o elemento propulsor da autonomia do sujeito político. E este sujeito toma a racionalidade moderna como sua verdade, que ao implicar no campo político faz da razão sua ferramenta de soberania, que tem por projeto não o desenvolvimento dos outros sujeitos, mas a manipulação e instrumentalização da existência humana comandada por poucos ou por aqueles que usam a democracia para sustentar o trabalho da necropolítica.

O trabalho da necropolítica compõe-se ao negar a alteridade. O Outro aparece como um atentado à vida do sujeito. A negação da alteridade é dada pela transgressão da alteridade, em que o outro estará fadado ao campo de visão do sujeito, que faz dele massa de manobra política para sustentar a sua malignidade. Se a ética em algum momento atuou como a reflexão dos costumes, ela agora passa a ser a presentificação desse costume como significação para barrar o desejo de subordinação do Outro ao sujeito, como aponta Noguera, Seixas e Alves (2019, p. 158).

\footnotetext{
O controle sobre as condições de vida e morte são atos soberanos. [...] o Estado de exceção e a relação de inimizade tornaram-se a base normativa do direito de matar. Em tais instâncias, o poder continuamente se refere e apela à exceção, à emergência e uma noção ficcional do inimigo. Inimigo tratado enquanto um outro que se torna uma ameaça a ser eliminada, segundo um tipo de norma ou regra que o torna passível de ser morto.
}

Esse inimigo sob a mira do Estado, geralmente pertence àquilo que modernamente chamamos de minorias. As minorias se constituem em grupos que se organizam para resistir às políticas governamentais de morte, por julgar pouco rentável diante do modelo de desenvolvimento econômico, especificamente no modo de sociedade neoliberal adotado, como é o caso dos negros, que historicamente eram subordinados aos seus senhores nos tempos da escravidão e que resistem ao racismo, ou ainda a população carcerária brasileira, que além de seus crimes e penas, é paralela e exponencialmente negra.

Assim, a respeito dessa população em referência mundial, percebemos que ela é "numerosa para o confinamento de presidiários, o controle social precisa de outros meios. Em tempos de devir-negro do mundo, a necropolítica anti-negros se apresenta como o novo meio de eliminação" (NOGUERA; SEIXAS; ALVES, 2019, p. 166). 


\section{EXPERIÊNCIAS CONTEMPORÂNEAS DE DESTRUIÇÃO HUMANA}

Ao adentrar nas experiências contemporâneas de destruição humana, faz-se necessário, identificar os envolvidos na contenda como sujeitos de negação ou afirmação da alteridade, possibilitando assim analisar a participação de cada um no sistema necropolítico.

Ao tratar dos sujeitos envolvidos na relação Estado-presidiários, ambos inseridos na esfera social como sujeitos de direitos e deveres, deve-se levar em conta que o Estado é o garantidor da ordem social. Dessa maneira, o Estado deverá aplicar e executar as penas e sanções que são impostas aos presidiários. Percebe-se que, em suma, parte dos presidiários são seres humanos que sobrevivem à própria sorte, ante a total ausência do poder público em diversos segmentos, entre os quais a Educação se revela o mais ausente. Nesse ponto denotase que o Estado se veste da figura do opressor - resistindo à ética da alteridade - e o presidiário incorpora a personalidade do sujeito oprimido: como outro negado nesta relação.

Em outras palavras, o ser humano verdadeiramente "torna-se um sujeito" — ou seja, separado do animal — na luta e trabalho pelos quais ele ou ela enfrenta a morte (entendida como a violência da negatividade). É por meio desse confronto com a morte que ele ou ela é lançado (a) no movimento incessante da história. Tornar-se sujeito, portanto, supõe sustentar o trabalho da morte. (MBEMBE, 2016, p. 125).

A partir do ingresso do sujeito no sistema carcerário, ele deixa de ser tratado como um sujeito de direitos e de deveres, perdendo, portanto, sua condição de humanidade, em razão do delito que cometeu, tendo que ser responsável pela própria sobrevivência. Transpassa qualquer consideração jurídico-filosófica a condição de não humanidade que é imposta aos transgressores da lei, tendo como punidor de tais transgressões justamente o garantidor, o Estado.

A subvalorizarão da vida humana na condição que é imposta ao cumpridor de pena é uma clara violação dos princípios humanos, tal qual a ética, pois o que se faz não é uma reprimenda em razão do crime cometido, e sim desqualificação da possibilidade de humanidade que esteja presente no indivíduo oprimido, como o Outro que está condenado a ser inimigo do Estado.

A Declaração Universal dos Direitos Humanos diz que:

Art. II: Todo ser humano tem capacidade para gozar os direitos e as liberdades estabelecidos nesta Declaração, sem distinção de qualquer espécie, seja de raça, cor, 
sexo, idioma, religião, opinião política ou de outra natureza, origem nacional ou social, riqueza, nascimento, ou qualquer outra condição.

$[\ldots]$

Art. V: Ninguém será submetido à tortura nem a tratamento ou castigo cruel, desumano ou degradante. (DECLARAÇÃO UNIVERSAL DOS DIREITOS HUMANOS, 2009, p. 05-06).

De acordo com dados extraídos do Departamento Penitenciário Nacional que fez o Levantamento Nacional de Informações Penitenciárias, no ano de 2017, publicado no ano de 2019, a população carcerária no Brasil correspondia a 726.354 pessoas, para 423.242 vagas, apresentando como déficit de vagas o exorbitante número 303.112 vagas, e como taxa de ocupação 171,62\%. E ainda evidenciou que a quantidade de crimes tentados/consumados pelos condenados e os que aguardam julgamento por cometerem crimes contra o patrimônio representa 234.866 do total levantado nas unidades que dispunham de tais informações.

Outro ponto a ser considerado é que a atual população carcerária no Brasil, quando se faz referência a etnia/cor, se desenha da seguinte maneira: 46,2\% são de cor/etnia parda, $35,4 \%$ cor/etnia branca e $17,3 \%$ de cor/etnia preta. Assim fica claro que a população carcerária negra no Brasil representa 63,5\%. Os números apresentados no levantamento na questão educacional quanto ao nível de escolaridade se moldam da seguinte forma: 51,3\% possuem o Ensino Fundamental Incompleto, 14,9\% com Ensino Médio Incompleto e 13,1\% com Ensino Fundamental completo, e 0,5\% possui Ensino Superior Completo.

Isso leva à seguinte inferência: que a população carcerária no Brasil majoritariamente é negra e possui baixo grau de escolaridade. O Estado passa a revelar sua contradição, pois, como mecanismo garantidor, este deveria garantir o acesso universal à Educação para a população, e que não o fazendo, a taxa de incidência no cometimento de crimes é extremamente elevada. Pois demonstra que pessoas com baixo nível de escolaridade estão mais propensas a ingressar na criminalidade, por estar numa sociedade que estimula o consumo, e adota como modelo econômico o neoliberalismo, uma vez que pressupõe Estado Mínimo e a alta concentração de riquezas numa parcela cada vez menor de indivíduos.

De acordo com os dados disponíveis no site do Ministério da Educação, na plataforma Educa Mais Brasil, sobre o índice de analfabetismo no Brasil, há uma pesquisa realizada pelo IBGE, no ano de 2017, em que revela que o índice de analfabetismo é de 7\%, cerca de 11,5 milhões de indivíduos acima de 15 anos de idade, e de analfabetismo funcional, que atinge cerca de $29 \%$ da população. Ou seja, mais de $40 \%$ da população brasileira economicamente ativa, aproximadamente 80 milhões de pessoas, se encontram excluídas das possibilidades de 
usufruir dos bens e serviços e contribuir economicamente para a sociedade brasileira, por não dispor do acesso garantido à escolarização e não possuir e conhecimento para atuar no mercado.

Nesse ponto, evidencia-se que a política de Estado, no que faz referência à população negra, pobre e analfabeta, é a necropolítica, pois, em termos econômicos, mostra-se mais barato adotar a política de morte que educar a população, ou ainda ofertar condições de inserção social e, por fim, a ressocialização aos egressos do sistema prisional.

Destarte, esse alto índice de analfabetismo provoca os graves problemas sociais e econômicos, como a falta de capacitação e formação técnica e profissional, gerando a exclusão social numa sociedade que naturaliza a miséria, o racismo estrutural, bem como o preconceito contra essa população que não consegue qualificação para um mercado de trabalho que exige cada vez mais conhecimentos específicos, devido ao nível tecnológico.

Consequentemente, esses indivíduos empurrados para a marginalidade do sistema social e econômico são os alvos da necropolítica como o modus operandi do Estado brasileiro de caráter neoliberal adota.

A valorização da vida humana fica em segundo plano, quando se tem prioridades econômicas que atendem apenas a uma determinada elite financeira, que detém o poder e influência suficiente para eleger e reeleger governos neoliberais e autoritários, sob a ótica de garantia do desenvolvimento econômico, se contrapondo ao desenvolvimento humano. "Havia também aqueles que nunca tinham saído. Em uma festa no palácio dos Bandeirantes, um político pergunta para um empresário: “—Você por aqui? E o empresário responde: —Eu estou sempre aqui. Vocês, políticos, que mudam.” (Documentário Democracia em Vertigem).

Segundo o jurista Nilo Batista (2018),

[...] na economia o arrogante discurso neoliberal levou um tranco. Sabemos agora o que mão invisível do mercado fazia depois do expediente. Mas a política genocida do neoliberalismo parece sobreviver a ele. A indústria do controle do crime responde um pouco por essa permanência. De outro lado, nunca o sistema penal acolitou tão visivelmente a acumulação capitalista.

O Estado reflete o modo de vida de uma sociedade neoliberal que apresenta em si uma incongruência insanável, e fomentadora da necropolítica, além de defender como parte da natureza do Estado neoliberal o Estado mínimo, que por sua vez não implementa as políticas públicas que são necessárias para atender a população cada vez mais excluída e consequentemente subordinada pelas forças coercitivas do Estado. 
O neoliberalismo econômico e político desencadeia o complexo fenômeno da criminalidade atual. Para acessar a demanda de consumo estimulada pelo sistema, o indivíduo excluído das condições de acesso à educação e qualificação profisssional lança mão da própria dignidade humana, perde o senso de responsabilidade — tal qual a responsabilidade levinasiana - e, para ter acesso aos bens de consumo, viola o patrimônio de outrem, para assim integrar-se ao modelo de sociedade estabelecido.

O acúmulo de condições que estabelecem o poder de morte que detém o Estado sob os presidiários, culmina com uma elevada taxa de mortalidade nas unidades prisionais brasileiras, chegando ao percentual de 15,2\% de mortos para cada 10.000 presidiários, conforme dados extraídos do Levantamento Nacional de Informações Penitenciárias (2019).

Assim, lançando mão de sua dignidade humana e de seus deveres em relação à sociedade, este rememora as perdas de antes do tempo de escravidão, "a condição de escravo resulta de uma tripla perda: perda de um lar, perda dos direitos sobre seu corpo e perda de status político. Essa perda tripla equivale à dominação absoluta, alienação ao nascer e morte social (expulsão da humanidade de modo geral)” (MBEMBE, 2016, p. 131).

\section{O MECANISMO DA NECROPOLÍTICA E A RESPOSTA DA ALTERIDADE}

O mecanismo da necropolítica oferece relações em estado de ruína, devido a sua política de morte, a sua assistência para fortalecer as desigualdades, exemplificado na população carcerária, e a violência institucionalizada. A violência aliena e compromete a vida em sociedade, na qual o Outro é visto como um sujeito de relação distante, gerando dilemas em nossa época contemporânea. Faz-se necessário buscar as questões fundamentais em Emmanuel Levinas para impedir que o dilema da violência seja incluído compreensivamente na relação Estado-Sociedade, ou ainda, Sujeito-Outro, para que se reestabeleça e se conserve veementemente o princípio da ética.

Assim, é importante trazer à questão o argumento de que "tudo aquilo que entendemos por violência, em todos os níveis, do mais brutal e explícito à violência coercitiva e socialmente sancionada do direito positivo estatal, e inclusive, a violência autoinfligida, repousa no fato exercido de negação de uma alteridade" (SOUZA, 2001, p. 08).

Pela violência compreende-se e se interpela a realidade, juntamente com o entendimento filosófico de como essa realidade se altera e se apodera de padrões de bem-estar social disfarçado, em que a violência assume até mesmo discursos que corroem o campo da 
alteridade - que é o campo em que todas as relações estão acontecendo, em grau de simultaneidade mínimo e máximo, que é ceifado em nível institucional. Inclusive nas relações em que a alteridade é negada, como a violência habitual no sistema carcerário brasileiro, que se exemplifica nos presos mortos dentro dos próprios presídios.

Desse modo, a necropolítica continua se afirmando e se institucionalizando por meio da violência contra a vida, e esta como objeto e refém de um sistema que viola o rosto do Outro partidariamente.

A violência pretende, como fim primeiro e último, a neutralização da alteridade, proibindo-lhe os recursos de existência. Para tanto, de acordo com Souza (2001), a violência passa a se constituir em polos de decisão individual ou social, e ainda de forma consciente ou em situação que incute inconsciência.

Entende-se que em nível de consciência há uma escolha clara, uma decisão premeditada que configura o agir e, em nível de inconsciência, há uma atitude inconsequente que compromete a condição de permanência do outro na vida propriamente dita, visto que "a maior das violências consiste em velar os vínculos profundos que qualquer ato violento tem com qualquer outro ato violento" (SOUZA, 2001, p. 09).

A necropolítica acoberta e legitima o discurso e a prática da violência, atingindo, dessa maneira, todos os níveis da vida, comprometendo o tempo presente e futuro, se interligando continuamente ao exercício da negação da alteridade. A alteridade é um apelo e um ordenamento manifestado por meio do Rosto do Outro. Para tanto, “O 'Tu não matarás' é a primeira palavra do rosto. Ora, é uma ordem. Há no aparecer do rosto um mandamento. [...] E eu, que sou eu, mas enquanto primeira pessoa, sou aquele que encontra processos para responder ao apelo" (LEVINAS, 1982, p. 80).

Interessa dizer que o Rosto da Alteridade assume fatos visíveis já citados nesta pesquisa, quando se evidencia que existe uma população carcerária que, além de estar sob os cuidados do Estado, está ainda refém de um órgão que potencializa a negligencia devido ainda às características históricas e políticas que carregam em si, como é o caso da população carcerária negra e com níveis de escolaridade limítrofes e ínfimos, fato que se ascende à criminalidade, levando à perda da noção de liberdade e responsabilidade.

$\mathrm{Na}$ tentativa de postular sobre o tema da alteridade em paralelo ao tema da necropolítica, toma-se posse do novo horizonte que se inaugura ao nível da consciência ética e política, a de que não podemos participar do assassinato e do suicídio coletivo comandado pelo império da sociedade democrática e neoliberal. 
Assim, a ética da alteridade propõe que os mecanismos violentos da necropolítica sejam reconsiderados e paralisados, visto que ela mesma é capaz de identificar os sujeitos que exercem e legalizam a violência e os sujeitos, em sua alteridade, em seu modo de se apresentar como o Outro em questão, e que padecem do sistema desde sua legalidade ao seu legítimo poder de praticar a violência sob o véu da justiça.

\section{REFERÊNCIAS}

BATISTA, Nilo. A cilada da militarização. Jornal do Brasil, 25 fev. 2018. Disponível em: https://www.jb.com.br/index.php?id=/acervo/materia.php\&cd_matia $=883881 \&$ dinamico $=1 \&$ preview=1. Acesso em: 05 abr. 2020.

DECLARAÇÃO UNIVERSAL DOS DIREITOS HUMANOS. UNIC/Rio/005, Janeiro 2009. Disponível em: https://nacoesunidas.org/wp-content/uploads/2018/10/DUDH.pdf. Acesso em: 05 abr. 2020.

LÉVINAS, Emmanuel. Ética e infinito. Lisboa: Edições 70, 1982.

LOVO, Carlos Mariano. La etica como filosofia primera en E. Levinas. Rev. Universidad Francisco Gavídia, San Salvador, n.1, jan. Ifev. 1999. Disponível em: http://www.ufg.edu.sv/ufg/theorethikos/Enero99/carlos.html. Acesso em: 11 abr. 2019.

MBEMBE, Achille. Necropolítica. Rev. do Programa de Pós-Graduação em Artes visuais, UFRJ. n. 32, 2016. Disponível em: https://revistas.ufrj.br/index.php/ae/article/view/8993. Acesso em: 30 mar. 2019.

\section{MINISTÉRIO DA JUSTIÇA E SEGURANÇA PÚBLICA. DEPARTAMENTO} PENITENCIÁRIO NACIONAL. Levantamento Nacional de Informações Penitenciárias. Atualização - Junho de 2017. Consultor: Marcos Vinícius Moura Silva. 2019. Disponível em: http://depen.gov.br/DEPEN/depen/sisdepen/infopen/relatorios-sinteticos/infopen-jun-2017rev-12072019-0721.pdf. Acesso em: 03 abr. 2020.

MINISTÉRIO DA EDUCAÇÃO. EDUCA MAIS BRASIL. Analfabetismo no Brasil. c2020. Disponível em: https://www.educamaisbrasil.com.br/enem/geografia/analfabetismono-brasil. Acesso em: 15 abr. 2020.

NOGUERA, Renato; SEIXAS, Rogério Luis, ALVES, Brunior Francisco. A necropolítica na iminência do devir-negro do mundo. Voluntas: Revista Internacional de Filosofia. UFSM, Santa Maria, v. 10, p. 150-167, 2019. Disponível em: https://periodicos.ufsm.br/voluntas/article/view/40049. Acesso em: 02 abr. 2019.

SOUZA, Lourival Robty Santos. Alteridade feminina. Sapere aude, Belo Horizonte, v. 10, n. 19, p. 389-397, jan./jun. 2019. Disponível em: http://periodicos.pucminas.br/index.php/SapereAude/article/view/19966/14984. Acesso em: 03 abr. 2019. 
SOUZA, Ricardo Tim. Três teses sobre a violência. Civitas - Rev.de Ciências sociais. Rio Grande Sul, ano 1, n. 2, dez. 2001. Disponível em:

http://revistaseletronicas.pucrs.br/ojs/index.php/civitas/article/view/72. Acesso em: 07 abr. 2019. 